\title{
Resilience in young people living with violence and self-harm: evidence from a Norwegian national youth survey
}

This article was published in the following Dove Press journal:

Psychology Research and Behavior Management

19 August 2015

Number of times this article has been viewed

\author{
Lihong Huang' \\ Svein Mossige ${ }^{2}$ \\ 'NOVA - Norwegian Social Research, \\ Oslo and Akershus University College \\ of Applied Sciences, ${ }^{2}$ Department of \\ Psychology, University of Oslo, Oslo, \\ Norway
}

\begin{abstract}
The aim of this article is to explore the relationship between resilience and the psychological problems of young people who reported being victims of violence and who engaged in self-harm. We used data from a national survey conducted in 2007 asking young people in Norway ( $\mathrm{N}=6,034$; ages $18-19$ years) about their experiences with violence during their childhood and during the past 12 months, and also about their mental health and experiences of self-harm. Our analyses revealed that resilience, as measured by the Resilience Scale for Adolescents, correlates significantly and negatively with psychological problems among all young people, and that this correlation is substantially stronger for those youths who reported violent experiences and those who engaged in self-harm.
\end{abstract}

Keywords: resilience, self-harm, violence, psychological problem

\section{Introduction}

Self-harm - also called self-injury, intentional self-injury, deliberate self-harm, or self-mutilation - has frequently been researched, and it is also treated in psychological and clinical practice under the umbrella of suicidal behaviors. Given that it is mostly a hidden behavior and hard to detect, the definition of self-harm in the previous literature is rather inconsistent; ${ }^{1}$ this inconsistency has prevented the accurate assessment of the prevalence of self-harm in the population. It is estimated that the percentage of young people who ever engage in self-harm constitute approximately $13 \%$ of adolescents in the United Kingdom, $17 \%$ of $14-21$-year-olds in Canada, $26 \%-37 \%$ of $9-12$ th graders in the United States, ${ }^{2}$ and $18 \%$ of young people aged $18-19$ years in Norway. ${ }^{3}$

Previous research has differentiated between suicidal self-harm (SSH) with an intention to die and non-suicidal self-harm (NSSH) without suicidal intent. Studies indicated associations between self-harm behaviors and individual, family, and societal/ ecological factors such as family dysfunction and conflict, peer bullying, intimidation in school, ${ }^{4}$ poverty, ${ }^{2}$ experiences of violence, and sexual abuse. ${ }^{3,5,6}$ Neighborhood social environment characterized by a high level of poverty, social exclusion, and socioeconomic deprivation, as well as the quality of social relationships, influence self-harm behaviors as well. ${ }^{7-10}$

Evidence from 21 participant countries that completed the World Mental Health Surveys initiated by the World Health Organization showed a strong association between physical and/or sexual abuse during childhood and self-harming behavior and/or suicidal thoughts occurring later in life. ${ }^{11,12}$ Some longitudinal and cross-sectional studies have found that abuse and neglect are direct and independent predictors of suicidal and self-harming behavior, even after controlling for depression, hopelessness, and other
Correspondence: Lihong Huang NOVA - Norwegian Social Research, Oslo and Akershus University College of Applied Sciences, Postbox 4 St Olavs plass, 0130 Oslo, Norway

Tel +4724II63458

Email lihong.huang@nova.hioa.no 
childhood adversities. ${ }^{13}$ A longitudinal cohort study found an association between bullying victimization and self-harm among young adolescents. ${ }^{14}$

Apparently, most of the previous research has focused on the risk factors associated with self-harm and little on the factors that may prevent or protect against this kind of behavior. Seen as a desirable behavioral adaptation despite adverse experiences, ${ }^{15}$ resilience has received considerable attention in recent years in psychological research on children and adolescents. It is understood as a personal trait inherent in an individual, or as a process or a phenomenon ${ }^{16}$ influenced by culture and context. ${ }^{17}$ The trait and process aspects are both present when regarding resilience as "both the capacity of individuals to navigate their way to health-sustaining resources [...] and a condition of the individual's family, community and culture to provide these health resources and experiences" in the face of adversity. ${ }^{18}$ Instead of looking at resilience as a process, or the "successful adaptation to adversity", ${ }^{19,20}$ we applied a more trait-like understanding of the concept as a point of departure for our analyses. We used the Resilience Scale for Adolescents (READ), which consists of five factors including family cohesion, personal dispositions as personal competence, social competence and structured style, and external support systems as social resources. ${ }^{21}$ The scale makes it possible to explore the relationship between each of these five dimensions of resilience and reported levels of psychological problems.

Using data from a national youth survey conducted in 2007 in Norway, we focused our analyses on the resilience of young people living with adversity, who had experienced violence and abuse in the past, and who also engaged in self-harm. We investigated these young people's degree of resilience, as well as examined each of the five factors included on the READ and their correlations with the youths' psychological health. We further explored how these correlations differed in association with young people's exposure to adversities. Our aim was to explore the potential of each of the five factors of resilience for reducing and/or preventing psychological problems among young people who reported being victims of violence and who engaged in self-harm. We expected that each of the five factors of resilience would be negatively correlated with the level of experienced adversities, as well as with level of psychological problems.

\section{Data and methods}

The data used in this study were obtained from the Norwegian youth survey on violence and abuse, which was conducted in $2007 .{ }^{22}$ The aim of the survey was to assess the prevalence of three different offences against children and youth: parental violence directed at the child; witnessing violence against parents; and experiencing sexual abuse. Students in their last year of education from 67 randomly selected upper secondary schools participated in the survey. The study obtained permission to perform this research from authorities at national level: the Norwegian Data Protection Official for Research (NSD) and the Norwegian Regional Ethics Committee for Medical and Health Research (REK), and permission from authorities both at municipal level and at the school level. As a result, 9,085 students were invited to participate in the survey during the months of February 2007 and March 2007, and 7,033 students responded with a response rate of $77 \%$. Here, we present the data analyses from 6,304 cases that had provided complete information regarding their sex, and who had completed the 28-item READ measuring resilience. Most of the respondents $(92 \%)$ were between the ages of 18-19 years and $58 \%$ of them were female.

\section{Measures of violence}

The survey includes data on three major forms of offences against children: non-physical violence (severe verbal bullying, threat of violence, and witnessing violence against their parents), as reported by 3,362 young people (53\%); physical violence (slap with open hands, fists, or being "beaten up"), as reported by 2,420 young people (38\%); and sexual abuse (unwanted touching, exposure, or sexual acts), as reported by 1,684 young people $(26.7 \%)$. The study investigated offences committed by adults at times before and/or after the student reached the age of 13 years, as well as those offenses committed by peers during the past 12 months and/ or prior to that time. Previous analyses of our data provided detailed statistical accounts on the violent experiences of Norwegian youths. ${ }^{3,23}$ The data revealed that over $60 \%$ of young people reported being victims of one or more of those forms of violence. The prevalence of reported violent experiences appears to be very high because we had counted all of the violent experiences reported by young people - ie, all three forms of violence (sexual, non-physical, and physical), three types of perpetrators (ie, parents, peers, and being a witness of violence at home), and in multiple arenas (home, school, and beyond). Among these students, 40.2\% were males. Females tended to report experiencing more verbal abuse (or witnessing verbal abuse) at home, while boys tended to report experiencing or witnessing more physical abuse by adults or peers. ${ }^{22}$ There was a clear overrepresentation of young people who reported experiencing violence and abuse among those who engaged in self-harm. ${ }^{3}$ We used an 
account of the combinations of the three forms of violence experienced by young people (ie, non-physical, physical, and sexual). Approximately $29 \%$ of the young people $(n=1,831)$ reported being victims of only a single form of violence; among them, 20\% were victims of sexual abuse, $57 \%$ were victims of non-physical or verbal abuse, and $22 \%$ were victims of physical abuse. Meanwhile, $26 \%$ of the youths in this study $(n=1,640)$ reported being victims of two forms of violence, with most of them being victims of a combination of non-physical and physical abuse. A total of $12.5 \%$ of the Norwegian youth ( $\mathrm{n}=785$ ) experienced poly-victimization, as they reported experiencing all three forms of violence.

\section{Measures of self-harm}

Self-harm $(n=1,183 ; 18.8 \%)$ is measured by non-zero responses to at least one of the three questions in the survey. The first question asks, "Have you at any time intentionally taken an overdose of pills or other medicine?" The second question asks, "Have you at any time tried to hurt yourself, eg, by cutting yourself?" The third question asks, "Have you at any time ended up in hospital because of any injury you have done to yourself intentionally?" All three questions had response options that included $0=$ never, $1=$ once, and $2=$ more than once. The data also contained information on suicide attempts, which was measured by non-zero responses to at least one of two questions: 1) "Have you at any time tried to kill yourself?" and 2) "Have you at any time ended up in hospital because you tried to kill yourself?" Responses were graded on a scale of $0=$ never, $1=$ once, or $2=$ more than once. A considerable number of young people reported both self-harm and suicidal attempts; these individuals were grouped into the $\mathrm{SSH}$ group $(\mathrm{n}=511 ; 8.1 \%)$. Among those young people who reported only self-harm $(\mathrm{n}=672 ; 10.7 \%)$, the majority engaged in cutting alone $(\mathrm{n}=609$; $9.7 \%)$, while 25 individuals engaged in overdose alone $(0.4 \%)$, and 38 individuals engaged in both cutting and overdose $(0.6 \%)$. However, applying the one-way analysis of variance (ANOVA) technique with a post hoc test on self-harm behaviors using "psychological problems" as the dependent variable had determined that those who reported only cutting, overdose, or both fell into one group. Eventually, we were looking at two groups of young people who reported self-harm: those who engaged in NSSH and those who engaged in SSH.

\section{Psychological problems}

Psychological problems were measured by a 12 -item short version of the Hopkins Symptom Checklist, ${ }^{24}$ which indicated whether various symptoms of depression and anxiety were experienced during the past week. The item responses fell on a four-point scale, with responses ranging from 0 ("not been troubled at all"), to 1 ("been a little troubled"), 2 ("been quite troubled"), and 3 ("been very much troubled"). The psychological problems variable was indicated by the mean score from the sum of the 12 Hopkins Symptom Checklist items. Higher values indicate poorer psychological health (or higher levels of psychological problems).

\section{Measures of resilience}

As a measure of resilience, we employed the READ, ${ }^{25}$ which contains 28 items; responses on this scale range from 1 ("completely disagree") to 5 ("completely agree") on a five-point Likert scale. Some previous research has suggested that there are four groups of protective factors that foster resilience among children and adolescents: individual factors; family factors; school factors; and community and cultural factors. ${ }^{26,27}$ Other research has identified three categories of factors that explain resilience: positive individual factors; family support; and a supportive environment outside the family. ${ }^{21}$ A previous analysis that was performed to validate the READ identified five factors of resilience among Norwegian youths using the same data. ${ }^{21}$ The five factors constituting resilience in our data include personal competence, social competence, structured style, family cohesion, and social resources. By applying principal component analysis to the 28 items on the READ, we achieved a fivefactor structure of resilience. Table 1 presents the five-factor structure of the READ with its corresponding factor loadings and the mean and standard deviation for each item - namely, "family cohesion", "personal competence", "social competence", "social resources", and "structured style". We used the five-factor structure to obtain five scores for resilience for each case by summing up the items of each factor and taking the mean (minimum as 1 and maximum as 5), where a higher value indicates a higher degree of resilience.

\section{Analysis methods}

Although a considerable number of our respondents were both victims of violence and individuals who engaged in selfharm behavior, one third $(n=1,908 ; 30.3 \%)$ of the respondents reported neither being a victim of violence nor engaging in self-harm. Our data analyses used this group of young people (those who were neither exposed to violence nor engaged in self-harm) as a point of comparison to the young people who reported violent experiences. Young people with different experiences of violence and self-harm behaviors were first grouped into nine mutually exclusive groups (see Tables 2 and 3). Second, we presented the means and standard devia- 
Table I The five-factor structure of resilience based on the READ scale: factor loadings and descriptive statistics of the items

\begin{tabular}{|c|c|c|c|}
\hline READ scale items & $\begin{array}{l}\text { Factor } \\
\text { loadings }\end{array}$ & Mean & $\begin{array}{l}\text { Standard } \\
\text { deviation }\end{array}$ \\
\hline \multicolumn{4}{|l|}{ Factor I: family cohesion } \\
\hline In my family, we agree on most things & 0.76 & 3.71 & 1.06 \\
\hline In my family, we support each other & 0.74 & 4.40 & 0.91 \\
\hline In my family, we like to find and do things together & 0.72 & 3.58 & 1.12 \\
\hline I have a very good time with my family & 0.72 & 4.54 & 0.85 \\
\hline In my family, we agree on what is important in life & 0.70 & 4.01 & 1.06 \\
\hline My family looks positively forward, even when sad things happen & 0.63 & 4.11 & 0.93 \\
\hline In my family, we have rules that simplify the every day & 0.60 & 3.12 & 1.11 \\
\hline \multicolumn{4}{|l|}{ Factor 2: personal competence } \\
\hline My faith in myself gets me through difficult times & 0.76 & 3.58 & 1.15 \\
\hline I feel I am proficient & 0.66 & 3.74 & 1.03 \\
\hline In adversity, I have a tendency to find something good I can grow on & 0.63 & 3.60 & 1.05 \\
\hline When I make a choice, I often know which is the right one for me & 0.59 & 3.82 & 0.97 \\
\hline I am satisfied with my life now & 0.55 & 4.19 & 1.00 \\
\hline I know how I will achieve my goal & 0.52 & 3.91 & 0.98 \\
\hline When it is impossible for me to change things, I stop pondering on them & 0.43 & 3.04 & 1.21 \\
\hline \multicolumn{4}{|l|}{ Factor 3: social competence } \\
\hline It is easy for me to find new friends & 0.76 & 3.94 & 1.06 \\
\hline I am good at talking to new people & 0.75 & 3.85 & 1.06 \\
\hline It is easy for others to have a good time with me & 0.67 & 4.33 & 0.80 \\
\hline I always find some comforting words to say to those who are sad & 0.63 & 4.03 & 0.92 \\
\hline I always find something funny to talk about & 0.57 & 3.82 & 0.97 \\
\hline My friends stick together & 0.42 & 4.30 & 0.88 \\
\hline \multicolumn{4}{|l|}{ Factor 4: social resources } \\
\hline I have some close friends/family members who really care about me & 0.64 & 4.79 & 0.58 \\
\hline I have some friends/family members who tend to encourage me & 0.63 & 4.51 & 0.81 \\
\hline I have some close friends/family members who appreciate my qualities & 0.56 & 4.52 & 0.77 \\
\hline I reach the goal if I am persistent & 0.52 & 4.52 & 0.78 \\
\hline I always have someone who can help me when I need it & 0.46 & 4.29 & 0.98 \\
\hline \multicolumn{4}{|l|}{ Factor 5: structured style } \\
\hline I always make a plan before I start something new & 0.77 & 3.23 & 1.12 \\
\hline I work best when I have made clear goals & 0.71 & 4.15 & 0.90 \\
\hline I am good at organizing my time & 0.64 & 3.14 & 1.16 \\
\hline
\end{tabular}

Notes: Principal component analysis - rotation method: varimax with Kaiser normalization. List wise N=6,304.

Abbreviation: READ, Resilience Scale for Adolescents.

tions of the resilience scores in these groups. We also used one-way ANOVA to test the significance of the resilience score among the groups, and post hoc tests were employed to detect significant mean differences between multiple groups. Third, we correlated resilience scores with the presence of psychological problems in the group of young people who reported violent experiences and who engaged in self-harm behaviors. We then compared the strengths of these correlations between groups to detect whether resilience acted as a supporting factor in the psychological health of young people in general, and in the psychological health of those who lived with adversity.

\section{Results}

It appears that as a trait-like property, the distribution of resilience differs among groups of young people living with adversity compared with those without any experiences of violence or self-harm. Table 2 presents the means and standard deviations of the five factors related to resilience, as well as the incidence of psychological problems among young people who reported violent experiences and those who engaged in self-harming behaviors. The respondents are presented as exclusive groups, depending on both the types of violent experiences reported and on their self-harm behaviors. Row 2 in Table 2 presents the group of youths who were used as a point of comparison: these youths did not report experience with violence or engaging in selfharming behaviors. The group with the highest resilience scores and the lowest number of psychological problems was that which included those youths who did not report any violent experiences or self-harm behaviors (Table 2; $\mathrm{n}=1,908 ; 30.3 \%)$. The group with the lowest resilience 
Table 2 Resilience and psychological problems among young people reporting violent victimization and engaging in self-harm

\begin{tabular}{|c|c|c|c|c|c|c|}
\hline $\begin{array}{l}\text { Groups of youth with violent } \\
\text { experiences and self-harming } \\
\text { behaviors }\end{array}$ & $\begin{array}{l}\text { Family } \\
\text { cohesion }\end{array}$ & $\begin{array}{l}\text { Personal } \\
\text { competence }\end{array}$ & $\begin{array}{l}\text { Social } \\
\text { competence }\end{array}$ & $\begin{array}{l}\text { Social } \\
\text { resources }\end{array}$ & $\begin{array}{l}\text { Structured } \\
\text { style }\end{array}$ & $\begin{array}{l}\text { Psychological } \\
\text { problems }\end{array}$ \\
\hline $\begin{array}{l}\text { No violent experiences and no } \\
\text { self-harm; } n=I, 908,30.3 \% \text { (as the } \\
\text { point of comparison) }\end{array}$ & $4.23(0.59)^{*}$ & $3.92(0.65)^{*}$ & $4.14(0.65)^{*}$ & $4.68(0.42)^{*}$ & $3.65(0.78)^{*}$ & $0.37(0.4 \mathrm{I})^{*}$ \\
\hline $\begin{array}{l}\text { Victim of a single form of violence } \\
\text { and no self-harm; } n=I, 574,25 \%\end{array}$ & $3.99(0.69)^{*}$ & $3.79(0.69)^{*}$ & $4.07(0.68)$ & $4.56(0.52)$ & $3.53(0.83)$ & $0.5 \mathrm{I}(0.47)^{*}$ \\
\hline $\begin{array}{l}\text { Victim of a single form of violence } \\
\text { and engaging in NSSH; } n=172,2.7 \%\end{array}$ & $3.82(0.74)^{*}$ & $3.4 \mathrm{I}(0.68)^{*}$ & $3.98(0.63)$ & $4.5 \mathrm{I}(0.53)$ & $3.4 I(0.8 I)$ & $0.86(0.5 \mathrm{I})^{*}$ \\
\hline $\begin{array}{l}\text { Victim of a single form of violence } \\
\text { and engaging in SSH; } n=85,1.3 \%\end{array}$ & $3.50(0.78)^{*}$ & $2.78(0.95)^{*}$ & $3.57(0.8 \mathrm{I})^{*}$ & $4.12(0.84)^{*}$ & $3.18(0.90)$ & $1.37(0.65)^{*}$ \\
\hline $\begin{array}{l}\text { Victim of two forms of violence } \\
\text { and no self-harm; } n=1,213,19.2 \%\end{array}$ & $3.82(0.8 \mathrm{I})^{*}$ & $3.73(0.72)^{*}$ & $4.07(0.69)^{*}$ & $4.50(0.59)^{*}$ & $3.44(0.86)^{*}$ & $0.63(0.54)^{*}$ \\
\hline $\begin{array}{l}\text { Victim of two forms of violence } \\
\text { and engaging in NSSH; } n=238,3.8 \%\end{array}$ & $3.56(0.86)^{*}$ & $3.36(0.74)^{*}$ & $3.88(0.68)^{*}$ & $4.34(0.67)$ & $3.27(0.88)$ & $0.87(0.53)^{*}$ \\
\hline $\begin{array}{l}\text { Victim of two forms of violence } \\
\text { and engaging in } \mathrm{SSH} ; \mathrm{n}=189,3 \%\end{array}$ & $3.26(0.99)^{*}$ & $3.06(0.87)^{*}$ & $3.76(0.83)^{*}$ & $4.02(0.83)$ & $3.27(0.90)$ & $1.37(0.73)^{*}$ \\
\hline $\begin{array}{l}\text { Victim of three forms of violence } \\
\text { and no self-harm; } n=426,6.8 \%\end{array}$ & $3.8 \mathrm{I}(0.79)^{*}$ & $3.70(0.72)^{*}$ & $4.12(0.68)^{*}$ & $4.48(0.57)^{*}$ & $3.5 \mathrm{I}(0.84)^{*}$ & $0.8 \mathrm{I}(0.58)^{*}$ \\
\hline $\begin{array}{l}\text { Victim of three forms of violence } \\
\text { and engaging in NSSH; } n=I 56,2.5 \%\end{array}$ & $3.43(0.90)^{*}$ & $3.33(0.74)^{*}$ & $3.86(0.66)$ & $4.32(0.60)^{*}$ & $3.27(0.82)$ & $\mathrm{I} .07(0.57)^{*}$ \\
\hline $\begin{array}{l}\text { Victim of three forms of violence } \\
\text { and engaging in } \mathrm{SSH} ; \mathrm{n}=203,3.2 \%\end{array}$ & $3.14(1.06)^{*}$ & $2.94(0.89)^{*}$ & $3.64(0.86)$ & $4.00(0.87)^{*}$ & $3.29(0.90)$ & $\mathrm{I} .63(0.74)^{*}$ \\
\hline
\end{tabular}

Notes: $N=6,304$. Methods: one-way analysis of variance using post hoc tests. *Denotes a mean that is significantly different from the other groups at a level of $P<0.05$. A nonsignificant mean difference was observed between the group of victims of a single form of violence with NSSH and those with SSH in terms of "social competence", "social resources", and "structured style"; between the group of victims of two forms of violence with NSSH and those with SSH in terms of "social resources" and "structured style"; and between the group of victims of three forms of violence with NSSH and those with SSH in terms of "social competence" and "structured style". Data are presented as the mean (standard deviation).

Abbreviations: NSSH, non-suicidal self-harm; SSH, suicidal self-harm.

Table 3 Correlation coefficients of the five resilience factors with respect to psychological problems among young people who reported being victims of violence and who engaged in self-harm

\begin{tabular}{|c|c|c|c|c|c|}
\hline $\begin{array}{l}\text { Groups of youths with violent } \\
\text { experiences and self-harming behaviors }\end{array}$ & $\begin{array}{l}\text { Family } \\
\text { cohesion }\end{array}$ & $\begin{array}{l}\text { Personal } \\
\text { competence }\end{array}$ & $\begin{array}{l}\text { Social } \\
\text { competence }\end{array}$ & $\begin{array}{l}\text { Social } \\
\text { resources }\end{array}$ & $\begin{array}{l}\text { Structured } \\
\text { style }\end{array}$ \\
\hline $\begin{array}{l}\text { No violent experiences and no self-harm; } \\
n=I, 908,30.3 \%\end{array}$ & $-0.218 * *$ & $-0.420 * *$ & $-0.247^{* *}$ & $-0.216 * *$ & $-0.165^{* *}$ \\
\hline $\begin{array}{l}\text { Victim of a single form of violence and } \\
\text { no self-harm; } n=I, 574,25 \%\end{array}$ & $-0.255^{* *}$ & $-0.463^{* *}$ & $-0.267^{* *}$ & $-0.217^{* *}$ & $-0.144^{* *}$ \\
\hline $\begin{array}{l}\text { Victim of a single form of violence and } \\
\text { engaging in NSSH; } n=172,2.7 \%\end{array}$ & $-0.315^{* *}$ & $-0.502 * *$ & -0.092 & $-0.305^{* *}$ & $-0.301 * *$ \\
\hline $\begin{array}{l}\text { Victim of a single form of violence and } \\
\text { engaging in } \mathrm{SSH} ; \mathrm{n}=85,1.3 \%\end{array}$ & $-0.369 * *$ & $-0.598 * *$ & $-0.367^{* *}$ & $-0.34 I^{* *}$ & $-0.232^{*}$ \\
\hline $\begin{array}{l}\text { Victim of two forms of violence and no } \\
\text { self-harm; } n=1,213,19.2 \%\end{array}$ & $-0.297^{* *}$ & $-0.433^{* *}$ & $-0.250 * *$ & $-0.224^{* *}$ & $-0.126 * *$ \\
\hline $\begin{array}{l}\text { Victim of two forms of violence and } \\
\text { engaging in NSSH; } n=238,3.8 \%\end{array}$ & $-0.132 *$ & $-0.373^{* *}$ & $-0.130 *$ & $-0.140^{*}$ & $-0.138^{*}$ \\
\hline $\begin{array}{l}\text { Victim of two forms of violence and } \\
\text { engaging in } \mathrm{SSH} ; \mathrm{n}=189,3 \%\end{array}$ & $-0.259 * *$ & $-0.495^{* *}$ & -0.136 & $-0.274 * *$ & $-0.273^{* *}$ \\
\hline $\begin{array}{l}\text { Victim of three forms of violence and } \\
\text { no self-harm; } n=426,6.8 \%\end{array}$ & $-0.332^{* *}$ & $-0.475^{* *}$ & $-0.216 * *$ & $-0.282^{* *}$ & $-0.190 * *$ \\
\hline $\begin{array}{l}\text { Victim of three forms of violence and } \\
\text { engaging in NSSH; } n=156,2.5 \%\end{array}$ & $-0.316^{* *}$ & $-0.474 * *$ & -0.097 & $-0.227 * *$ & $-0.217^{* *}$ \\
\hline $\begin{array}{l}\text { Victim of three forms of violence and } \\
\text { engaging in SSH; } n=203,3.2 \%\end{array}$ & $-0.284^{* *}$ & $-0.519 * *$ & $-0.199 * *$ & $-0.258^{* *}$ & $-0.301 * *$ \\
\hline
\end{tabular}

Notes: *Correlation coefficient significant at the $P<0.05$ level; **correlation coefficient significant at the $P<0.01$ level. List wise $\mathrm{N}=6,304$.

Abbreviations: NSSH, non-suicidal self-harm; $\mathrm{SSH}$, suicidal self-harm. 
scores across all five dimensions and those with the highest rate of psychological problems was the group of young people who were victims of multiple forms of violence and those who also engaged in SSH (Table 2; $n=203 ; 3.2 \%$ ). The groups with substantial psychological problems (with means $>1.0$ ) were those who engaged in SSH and those who were victims of multiple forms of violence. Not all mean differences of resilience between the groups were statistically significant. However, we observed a trend of decreasing resilience scores among the groups with increasing forms of violent experiences and self-harm behaviors.

Moreover, our analyses showed that resilience as a trait increases the potential to reduce psychological problems as the level of adversity increases. Table 3 presents the correlation coefficients of the five resilience factors in association with psychological problems among young people who reported being victims of violence and those who engaged in self-harm. The group with neither an experience of violence nor those reporting self-harm behaviors (see row 2 in Table 3) can be regarded as a reference group of "normal" young people when compared with those young people living with adversity and engaging in self-harm behavior. First, all five resilience factors were negatively associated with psychological problems among young people - ie, the higher the degree of resilience, the lower the prevalence of psychological problems. Second, nearly all correlation coefficients were statistically significant, except for the groups featuring self-harm behaviors (NSSH youths who experienced a single form of violence, those NSSH youths who experienced all three forms of violence, and those SSH young people who experienced two forms of violence).

Third, compared with the group of young people who neither experienced violence nor engaged in self-harm (row 2 in Table 3; n=1,908), we observed a general increase in the correlation coefficients of all five resilience factors as they related to the presence of psychological problems in all groups; they also increased with respect to adversity and self-harm. While this was the case for all five factors, the resilience factor of personal competence had the strongest negative correlation coefficients (when compared with the other resilience factors) with the prevalence of psychological problems among normal young people. The correlations of personal competence were especially strong for those groups of SSH youths who experienced a single form of violence ( $r=-0.598)$, those SSH youths who experienced three forms of violence ( $r=-0.519$ ), and those NSSH youths who experienced a single form of violence $(r=-0.502)$.

\section{Conclusion}

The aim of this study was to explore resilience as a trait and its capacity for reducing and/or preventing psychological problems among young people who reported being victims of violence and who engaged in self-harm. Our analyses provided some new evidence regarding the resilience of young victims of violence and those who engaged in selfharm behaviors, in comparison to young people with neither violent experiences nor self-harm. We observed three striking features of resilience among young people living with adversity and self-harm. First, it was found that resilience negatively and significantly correlates with the presence of psychological problems among young people in general. These correlations were particularly strong for the groups of young people who reported being victims of violence and who also engaged in self-harm. Second, all the five dimensions or factors of resilience are generally lower for young people reporting victimization of violence than for those reporting no violent experiences. In the groups of young people who were victims of violence, resilience decreased in association with increases to exposure of different forms of violence. The lowest level of resilience was found in the group of young people who reported being both a victim of multiple forms of violence and who engaged in SSH. This indicates that resilience may protect against being exposed to adversities (eg, self-harm). Third, the five resilience factors had different strengths in terms of their negative correlations with the presence of psychological problems among all groups of youths, which can imply that the protective effect of resilience may be different for young people with different patterns of victimizations of violence and self-harm behaviors.

Our study offers novel insights, as it looks into resilience as both a trait of young people and as a capacity that can be built on in the face of adversity. The results have significant implications for practitioners working with young people. Working at an individual level, the dimension of personal competence seems important to relate to. Practitioners should also ask what kinds of social resources could be reinforced or implemented to prevent or reduce psychological problems among young people exposed to violence. Measures or strategies that are aimed at prevention or counseling initiatives that specifically target young people experiencing violence should consider multiple approaches and cross-sectoral cooperation. This means that family members at home, teachers and students at school, health care personnel, psychologists, and social workers at local communities should work together whenever matters concern young people exposed to adversities. For young victims of violence and those who also 
engage in self-harm behaviors, all five resilience factors are important protective factors for psychological health; therefore, working to develop young people's resilience, especially in terms of personal competence, should be a priority in an effort to comprehensively build upon and establish general resilience in these at-risk groups.

However, the major limitation of this study has to be acknowledged: it is a cross-sectional study; as such, it did not allow us to study resilience as a process. This ultimately restricts our aims and analyses from making inferences about the causal relationships between variables. Instead, our study utilizes the strength of the data (its large sample size), allowing us to analyze the subgroups based on various types of adversities and resilience factors.

\section{Acknowledgment}

English-language editing of this manuscript was provided by Journal Prep.

\section{Disclosure}

The authors have no conflicts of interest to disclose.

\section{References}

1. Chandler A. Self-injury as embodied emotion work: Managing rationality, emotions and bodies. Sociology. 2012;46(3):442-457.

2. Greydanus DE, Shek D. Deliberate self-harm and suicide in adolescents. Keio J Med. 2009;58(3):144-151.

3. Mossige S, Huang L, Straiton M, Roen K. Suicidal ideation and selfharm among youths in Norway: associations with verbal, physical and sexual abuse. Child and Family Social Work. 2014.

4. McMahon EM, Reulbach U, Keeley H, Perry IJ, Arensman E. Reprint of: Bullying victimisation, self harm and associated factors in Irish adolescent boys. Soc Sci Med. 2012;74(4):490-497.

5. Dube SR, Anda RF, Felitti VJ, Chapman DP, Williamson DF, Giles WH. Childhood abuse, household dysfunction, and the risk of attempted suicide throughout the life span: findings from the Adverse Childhood Experiences Study. JAMA. 2001;286(24):3089-3096.

6. Yates TM, Carlson EA, Egeland B. A prospective study of child maltreatment and self-injurious behavior in a community sample. Dev Psychopathol. 2008;20(02):651-671.

7. Groholt B, Ekeberg Ø, Haldorsen T. Adolescent suicide attempters: what predicts future suicidal acts? Suicide Life Threat. Behav. 2006; 36(6):638-650.

8. Adler PA, Adler P. The demedicalization of self-injury from psychopathology to sociological deviance. Journal of Contemporary Ethnography. 2007;36(5):537-570.

9. Bernburg JG, Thorlindsson T, Sigfusdottir ID. The spreading of suicidal behavior: The contextual effect of community household poverty on adolescent suicidal behavior and the mediating role of suicide suggestion. Soc Sci Med. 2009;68(2):380-389.
10. Fergusson DM, Woodward LJ, Horwood LJ. Risk factors and life processes associated with the onset of suicidal behaviour during adolescence and early adulthood. Psychol Med. 2000;30(1):23-39.

11. Bruffaerts R, Demyttenaere K, Borges G, et al. Childhood adversities as risk factors for onset and persistence of suicidal behaviour. $\mathrm{Br} \mathrm{J}$ Psychiatry. 2010;197(1):20-27.

12. Stein DJ, Chiu WT, Hwang I, et al. Cross-national analysis of the associations between traumatic events and suicidal behavior: findings from the WHO World Mental Health Surveys. PloS One. 2010;5(5):e10574.

13. King CA, Merchant CR. Social and interpersonal factors relating to adolescent suicidality: a review of the literature. Arch Suicide Res. 2008;12(3):181-196.

14. Fisher HL, Moffitt TE, Houts RM, Belsky DW, Arseneault L, Caspi A. Bullying victimisation and risk of self harm in early adolescence: longitudinal cohort study. BMJ. 2012;344:e2683.

15. Glantz MD, Johnson JL. Resilience and Development: Positive Life Adaptations. Springer Science and Business Media; 1999.

16. Luthar SS. Resilience And Vulnerability: Adaptation in the Context of Childhood Adversities. Cambridge University Press; 2003.

17. Theron LC, Donald DR. Educational psychology and resilience in developing contexts: a rejoinder to Toland and Carrigan (2011). School Psychology International. 2013;34(1):51-66.

18. Ungar M. Resilience across cultures. Br J Soc Work. 2008;38(2): $218-235$.

19. University of Nebraska - Lincoln. Carr K. Examining the Role of Family and Marital Communication in Understanding Resilience to Familyof-Origin Adversity. Communication Studies Theses, Dissertations, and Student Research; 2012. Available from: http://digitalcommons. unl.edu/cgi $/$ viewcontent.cgi? article $=1022 \&$ context $=$ commstuddiss . Accessed June 26, 2015.

20. Zautra AJ, Hall JS, Murray KE. Resilience: A new definition of health for people and communities. In Reich JR, Zautra AJ, Hall JS, editors. Handbook of Adult Resilience. New York: Guilford; 2010;3-30.

21. von Soest T, Mossige S, Stefansen K, Hjemdal O. A validation study of the resilience scale for adolescents (READ). Journal of Psychopathology and Behavioral Assessment. 2010;32(2):215-225.

22. Mossige S, Stefansen K. Vold og overgrep mot barn og unge: En selvrapporteringsstudie blant avgangselever i videregående skole [Violence and abuse against children and young people: A self reporting study among last year students at upper secondary schools]. NOVA Rapport 20. 2007;7. Norwegian.

23. Huang L, Mossige S. Academic achievement in Norwegian secondary schools: the impact of violence during childhood. Social Psychology of Education. 2012;15(2):147-164.

24. Wichstrøm L. Social, psychological and physical correlates of eating problems. A study of the general adolescent population in Norway. Psychol Med. 1995;25(3):567-579.

25. Hjemdal O, Friborg O, Stiles TC, Martinussen M, Rosenvinge JH. A new scale for adolescent resilience: grasping the central protective resources behind healthy development. Measurement and Evaluation in Counseling and Development. 2006:84-96.

26. Noltemeyer AL, Bush KR. Adversity and resilience: a synthesis of international research. School Psychology International. 2013; 34(5):474-487.

27. Williams J, Nelson-Gardell D. Predicting resilience in sexually abused adolescents. Child Abuse and Neglect. 2012;36(1):53-63. 


\section{Publish your work in this journal}

Psychology Research and Behavior Management is an international, peerreviewed, open access journal focusing on the science of psychology and its application in behavior management to develop improved outcomes in the clinical, educational, sports and business arenas. Specific topics covered include: Neuroscience, memory \& decision making; Behavior modification \& management; Clinical applications; Business \& sports performance management; Social and developmental studies; Anima studies. The manuscript management system is completely online and includes a quick and fair peer-review system. Visit http://www.dovepress. com/testimonials.php to read real quotes from published authors.

Submit your manuscript here: http://www.dovepress.com/psychology-research-and-behavior-management-journal 